\title{
PROFESSORES, ALUNOS E SUAS FAMÍLIAS: UMA ANÁLISE DA ESCOLA A PARTIR DE IDÉIAS DE BASIL BERNSTEIN
}

\section{TEACHERS, STUDENTS AND THEIR FAMILIES: AN ANALYSIS OF THE SCHOOL FROM IDEAS OF BASIL BERSNTEIN}

\section{Cristina Spolidoro FREUND*}

Resumo: Pretende-se, neste artigo, articular a pedagogia visível e invisível e conceitos sobre a escola, de Bernstein, a questões levantadas por Nogueira (1998) e Resende (2006) sobre a escolha de escolas pelos pais e a relação família e escola, e refletidas por Contreras (2002) e Cortesão (2006) sobre a atuação docente. Na primeira parte, apresentando conceitos de pedagogia visível e invisível de Bernstein (1984), o trabalho aborda as mudanças nas demandas de famílias de determinados segmentos de classe média, comparando-as às demandas de outras frações da sociedade. Mostra que famílias entram em conflito com suas próprias idéias a respeito da escolarização dos filhos, utilizando os conceitos de Bernstein sobre pedagogias visível e invisível e as implicações da busca de uma nova propriedade como posse de habilidades valorizadas e disponibilizadas nas instituições educacionais ao longo da escolarização. $O$ texto aborda as diferentes manifestações desse conflito na escola. Num segundo momento, apresenta conceitos sobre a escola, de Bernstein (1996), relacionando-os aos anteriores e apresentando sugestões para que os professores lidem com as demandas atuais em relação à escola e com as pressões geradas pela visão de educação enquanto mercado, de forma a procurar não coolaborar para o aumento das desigualdades sociais, trazendo as

* Especialista em Psicopedagogia Diferencial. Coordenadora de Ensino do Colégio Sion, RJ. Professora do Curso de Especialização em Psicopedagogia do Instituto Brasileiro de Medicina de Reabilitação (Uni-IBMR). E-mail: csfreund@gmail.com 
contribuições de Contreras (2002), Cortesão (2006), Canário (2005) e Mainardes (2007). A autora apontará o uso de práticas pedagógicas mistas na sala de aula e o conceito de professor como investigador-social-crítico como possíveis contribuições para a construção de uma escola democrática.

Palavras-Chave: Relações família-escola. Autonomia docente. Educação e mercado. Pedagogia visível e invisível.

Abstract: This article intends to articulate the visible and invisible pedagogy and concepts of Bernstein on the school to some questions pointed by Nogueira (1998) and Resende (2006) on the choice of schools by the parents and the relation family - school, and reflected by Contreras (2002) and Cortesão (2006) on the teaching acting. In the first part, presenting concepts of visible and invisible pedagogy of Bernstein (1984), the work mentions the changes in the families' demands of some middle class segments comparing them to the demands of other sectors in society. It shows that families get in conflict with their own ideas regarding to their children schooling by using the Bernstein's concepts on visible and invisible pedagogy and the implications of the search of a new property as the possession of valued and available skills in the education institutions during the schooling. The text also mentions the different demonstrations of this conflict in the school. In the second part, it presents Bernstein' school concepts (1996) relating them to the previous ones, as well as presenting suggestions to the teachers in order to deal with the current school demands and with the pressures produced by the view of education as a market, thus not contributing to the increase of the social inequalities, bringing the contributions of Contreras (2002), Cortesão (2006), Canário (2005) and Mainardes (2007). The author will point the use of pedagogical mixed practical in the classroom and the 
concept of teacher as a critical-social investigator as possible contributions to build a democratic school.

Keywords: Family-school relations. Teachers'autonomy. Education and market. Visible and invisible pedagogy.

\section{INTRODUÇÃO}

A teoria sociológica muito tem a contribuir para que os professores possam situar os problemas que vivem hoje, no exercício de sua função, na relação com as famílias e em relação às expectativas que apresentam sobre a escola, às suas próprias expectativas sobre o como e o para que educar e como conjugar essas crenças com as demandas das famílias e da sociedade.

Quem atua em escolas hoje, no Brasil, talvez vivencie questões relacionadas às demandas por vezes contraditórias das famílias. Desejam uma educação de qualidade, o que, dependendo do tipo de família, pode assumir significados muito diferentes: acesso dos filhos ao ensino superior oferecido por Universidades concorridas, à vasta cultura geral, à formação de competências necessárias à sobrevivência em um mercado de trabalho cada vez mais exigente e seletivo. Além dessas, agregam-se novas demandas, delegadas à escola pelo Estado e pela própria família, como, conforme Tedesco e Tenti Fanfani (2004): transmitir valores, fornecer "contenção afetiva, orientar para um projeto de vida", demandas essas que podem se tornar pontos de tensão entre famílias e escolas.

Neste texto pretende-se, no primeiro momento, utilizar os conceitos de Bernstein para identificar e refletir sobre algumas das tensões vivenciadas pela escola hoje, que têm sua manifestação na relação com a família, demonstrando, entretanto, que sua origem encontra-se no macro-social: a disputa entre uma escola legitimada pelo mercado e aquela orientada pelo conhecimento, quando utilizam pedagogias visíveis, e a tensão entre a formação integral da pessoa e as demandas sociais, quando utilizam pedagogias invisíveis. A autora relaciona os tipos de famílias, de classes médias e populares às suas demandas escolares; baseando-se nos conceitos de antiga e nova classe média, de Basil Bernstein (1984, 1996), analisa a origem de algumas dessas demandas e os motivos de conflito com a escola. Utiliza con- 
ceitos das pedagogias visível e invisível, de Bernstein (1984; 1996); contribuições de Forquin (1993), Tedesco e Tenti Fanfani (2004); e pesquisas de Nogueira (1998) e Resende (2006).

Num segundo momento, a autora estabelece relações entre questões originadas no macro-social, sobre a função e objetivos da escola, às mudanças que essas novas visões - de performance, competitividade e mercantilização da educação - trazem para a atuação docente e o cotidiano escolar, contribuindo para a exclusão de alunos. Introduz sugestões sobre como os professores podem minimizar os impactos dessas questões, utilizando pesquisas de Resende (2006) e Nogueira (1998), e trabalho de Contreras (2002), Cortesão (2006), Mainardes (2007) e Canário (2005).

Concluindo, a autora adianta que, ainda que a escola se mantenha como mecanismo de reprodução, conforme Bernstein, os professores podem, enquanto profissionais, assumir o papel de "investigadores-atores-críticos" (CORTESÃO, 2006) e, coletivamente, podem voltar a se apropriar da construção de sentido de seu ofício, assumindo uma educação mais justa e democrática, utilizando-se de dispositivos de diferenciação pedagógica e de práticas pedagógicas mistas (MAINARDES, 2003).

\section{A RELAÇÃO FAMÍLIA E ESCOLA ANALISADA ATRAVÉS DA TEORIA DE BERNSTEIN}

Conforme Bernstein declara em seu artigo Classes e pedagogia: visível e invisível $^{1}$ (1984, p. 28-29), a ideologia da classe média foi institucionalizada primeiro na escola pública, onde garantiu, junto com a família, a reprodução cultural, num modelo em que as relações de indivíduos com sua classe apresentavam papéis rígidos e muito bem delimitados. Esperava-se da escola transformar todos os alunos em cidadãos capazes de exercer um papel na sociedade e buscar progredir dentro de limites definidos, conquistando propriedades, bens de natureza física. Para essa antiga classe média, seu papel e o da escola eram bem claros e delimitados; jovens e crianças tinham também um papel claro na hierarquia familiar, escolar e social. Tais famílias, representantes desse extrato da classe média, ainda se fazem

${ }^{1}$ Para maiores esclarecimentos sobre Pedagogias visíveis e invisíveis, consultar Santos (2003) e Mainardes (2007).

Olhar de professor, Ponta Grossa, 11(1): 43-62, 2008 Disponível em <http://www.uepg.br/olhardeprofessor $>$ 
representar nas escolas, em cada vez menor número. A pedagogia que atendia a essa escola - pública e/ou privada - era a visível, ou seja, o professor ensinava disciplinas claramente delimitadas entre si e a ele cabia determinar o tempo destinado ao ensino de cada conteúdo, o ritmo de aprendizagem; os alunos, por sua vez, sabiam como seriam avaliados ao final de cada período. Era possível comparar alunos entre si e entre as escolas.

Essa pedagogia, porém, apresenta suas questões. Forquin (1993, p. 90) destaca de Bernstein que a rígida hierarquização e fronteira das disciplinas provoca, nas crianças, a "cristalização precoce da identidade cultural", do trabalho e das hierarquizações entre comunidades científicas. Desde cedo, se diz: "Gosto de Matemática, mas detesto História", ou vice-versa, mantendo-se as divisões entre saberes, divisões essas que são culturais, não-naturais do conhecimento humano e que hierarquizam as disciplinas conforme seu prestígio no mundo do trabalho. A essa rígida divisão, Bernstein denomina de classificação. Além disso, como essa é uma escola que centra a atividade no professor, este tem o poder de determinar a forma, ritmo, velocidade e seqüência de transmissão dos conhecimentos. É ele quem avalia. A isso, Bernstein chama enquadramento.

A pedagogia visível produz grande estratificação e competitividade entre os alunos, que se situam acima, abaixo e na média. Se isso permite aos pais acompanharem o progresso de seus filhos, também contribui para o reforço das dificuldades de alguns e para o exacerbamento da competição. Como as classes são percebidas como homogêneas, não se consideram os diferentes tempos de aquisição ou construção dos conceitos dos alunos, e muitos acabam não acompanhando o ritmo da escola. É necessário então um acompanhamento desse estudo pela família, o que Bernstein define como ter a família como um "segundo lugar de aquisição" (1996, p.112-113). Quando a família não consegue suprir esse apoio, o mesmo é terceirizado, em especial por famílias de classe média. Bernstein denomina compassamento à velocidade esperada de aquisição dos conteúdos. Alerta que essa regra atua como um princípio de seleção sobre os que adquirem o código pedagógico da escola ou não, e para ele "esse é um princípio de seleção que tem sua base na classe social" (idem, p. 114-115), porque é baseado na velocidade de aquisição de crianças da classe média, que têm no lar esse segundo lugar de aquisição.

Entretanto, esse tipo de pedagogia passou a não atender mais plenamente a uma nova fração da classe média, que, devido "ao au- 
mento da complexidade da divisão de trabalho do controle simbólico ou cultural, apropriado por esta classe" (BERNSTEIN, 1984, p. 28), vive uma mudança no conceito de propriedade, passando a valorizar mais um determinado tipo: aquele que toma a forma de posse psicologizada de habilidades a serem disponibilizadas pela instituição escolar, habilidades essas que se definem como formas especializadas de comunicação. Esse segmento da nova classe média teve sua ideologia institucionalizada em pré-escolas particulares (ibid, p. 28). Há possibilidade de papéis mais flexíveis, de construírem diferentes identidades, de grande mobilidade social, através do conceito da meritrocracia. Tal ideologia é representada pela pedagogia invisível, assim definida por Lucíola Santos:

No caso das pedagogias invisíveis, as relações e regras são implícitas e não são conhecidas pelo aluno. É que, neste último caso, a prática pedagógica, suas regras e critérios são derivados de teorias complexas sobre o desenvolvimento da criança e do adolescente, teorias da lingüística e da gestalt, em alguns casos, teorias psicanalítica. (SANTOS, 2003, p. 29-30).

Ou seja, uma vez que o progresso da transmissão deixa de ser baseado no tempo que se considera necessário para realizar o ensino e passa a se basear em teorias do desenvolvimento humano, nem a criança, nem suas famílias têm como conhecer as regras de seqüenciamento e compassamento, pois dependem de conhecimentos do transmissor (o professor) sobre teorias adotadas pela pedagogia (por exemplo, as cognitivistas, baseadas em Piaget). Inaugura-se uma pedagogia centrada na atividade da criança, enquanto comportamento observável da mesma, e que se mostra visível através do jogo. $\mathrm{O}$ professor utiliza-se do conceito de prontidão para definir a seqüência de atividades a serem propostas aos alunos e seu papel é o de facilitar a aquisição da aprendizagem, que só pode ser realizada pelo aluno. Essa pedagogia favorece o princípio da autonomia e a integração entre as áreas de saber, através da diminuição da classificação; diminui o compassamento, contemplando diferentes ritmos de aprendizagem; e permite uma flexibilização de papéis por parte dos alunos. Para avaliar o aluno, o professor precisará conhecer aspectos muito mais complexos que os avaliados nas pedagogias visíveis, estimulando os alunos a "tornarem visíveis suas características únicas." (BERNSTEIN, 1984, p. 28). 
A pedagogia invisível atende ao segmento da classe média que trabalha com os campos do controle simbólico e não no campo da produção, que permite aos alunos a aquisição daquelas formas especializadas de comunicação, necessárias a seu sucesso (BERNSTEIN, 1984). Esse segmento da classe média é aquele no qual se originam famílias que entram em conflito, conforme seus filhos progridem na escola. Costumam considerar as escolas construtivistas ${ }^{2}$ adequadas durante determinado período, por favorecerem o desenvolvimento de habilidades necessárias ao novo mercado, por diminuírem as fronteiras entre as disciplinas, integrando o conhecimento, de forma que os jovens tenham ferramentas para agiram num mundo onde precisam circular entre diversos saberes. Conforme os filhos vão crescendo, ficam em dúvida quanto ao tipo de instituição, uma vez que concursos públicos (inclusive vestibulares) baseiam-se em pedagogias visíveis (BERNSTEIN, 1984, p. 31), em um conhecimento dividido em fronteiras bem definidas (classificadas) e muito formalizado.

Bernstein, portanto, fornece uma explicação bastante plausível para um dos motivos que levam as famílias a entrarem em conflito com a escola, chegando a mudar de escola no meio do processo escolar de seus filhos. Essas famílias defenderiam uma Educação Infantil e, talvez, uma primeira fase do Ensino Fundamental em escolas consideradas progressistas e, depois, ou cobrariam da instituição mudanças, ou matriculariam os filhos em escolas tradicionais, consideradas por eles de ensino forte. Outros autores contribuem para essa questão da escolha, baseada na classe social das famílias e seus objetivos. Nogueira (1998) sintetizou as descobertas de pesquisa realizada na Inglaterra por Stephen Ball, Sharon Gewirtz e Richard Bowe (1995, apud NOGUEIRA, 1998). Ela afirma que os pais desse segmento da classe média seriam, basicamente, os do tipo "privileged/skilled choosers" (NOGUEIRA, 1998, p. 44), ou seja, aqueles que se ocupam por um bom tempo na escolha da escola dos filhos, que conseguem identificar os diferentes sistemas escolares, podendo analisar o projeto político pedagógico, estratégias de avaliação, atuação dos professores. Buscam escolas de elite, recorrendo a seus relacionamentos sociais para garantir, quando necessário, o ingresso à instituição desejada, procurando também a escola adequada para cada filho (a),

${ }^{2}$ São denominadas escolas construtivistas as que apresentam pedagogias centradas nos alunos, com suportes teóricos de psicologia cognitiva ou sócio-interacionista, entre outras. 
e sua escolha final se dá pelo "feeling" do local, baseado no clima institucional e no conjunto das avaliações anteriores, inclusive, "ao tipo e estado do prédio, ao ethos do estabelecimento." (NOGUEIRA, 1998, p. 44). É possível que as famílias privilegiem os resultados acadêmicos das escolas ou, então, optem por valorizar o clima das escolas e a capacidade de desenvolver diversas potencialidades dos alunos. Privilegiando os resultados, a família se posiciona como valorizando a lógica que pretende instrumentalizar os alunos para o sucesso escolar e social. No segundo caso, a família se mostra mais preocupada com o desenvolvimento integral da criança.

Nogueira argumenta que as famílias têm critérios tão complexos de escolha que, por vezes, mostram-se ambíguas ou até mesmo equivocadas (ibid., p.44). Isso se explica, segundo a autora, pelo fato de que "quanto maior a capacidade de escolha, maior é a exigência dos pais e a dificuldade de escolher entre os diferentes estabelecimentos, porque, em geral, nenhum deles lhes parece ser perfeito." (ibid., p. 44). Em concordância com a idéia defendida por Bernstein (1984), a ênfase da escolha muda, conforme a idade e escolarização dos filhos aumentam.

Entretanto, Bernstein argumenta que conflitos podem se manifestar mesmo com a troca de escolas, uma vez que alunos que passam uma boa parte de sua escolarização em escolas com pedagogia invisível costumam apresentar dificuldades em se adaptar à pedagogia visível, na qual o aluno precisa se adequar a novas exigências disciplinares e pedagógicas. Não só os alunos, mas também seus pais estavam acostumados a uma pedagogia que respeita ritmos e possibilidades e valoriza os progressos de seu filho, e precisam se adaptar ao ritmo e exigência de provas, e a assumir-se enquanto o segundo lugar de aquisição. Bernstein (1996) justifica a necessidade dessa função da família através da regra de compassamento, já mencionada neste artigo. E, para que a família se torne um segundo lugar de aquisição, é necessário que a escola se reproduza no lar, o que ocorre através da prática do dever de casa.

É possível que a família não consiga providenciar o que é necessário para que a criança acompanhe o ritmo proposto por uma pedagogia visível. Entretanto, mesmo escolas particulares, consideradas "tradicionais", incorporaram princípios da psicologia cognitiva em relação à seqüência de conteúdos, e aplicações desta e de outras teorias em relação à didática de diferentes disciplinas. Assim, essas 
escolas se mantêm como representantes da pedagogia visível na maior parte do enquadre, mas mesclam elementos da pedagogia invisível em relação a conceitos de prontidão, ou de desenvolvimento cognitivo, e, dessa forma, interrompem as possibilidades de atuação pedagógica da família. Benstein afirma que esse fato é mais comum em relação às classes populares, uma vez que para ele a maior parte das famílias de classe média consegue entender e aceitar os valores e métodos da pedagogia invisível, e, quando a criança não obtém o desenvolvimento esperado, ela provê um "sistema educacional de sustentação" (BERNSTEIN, 1984, p. 34), providenciado via esforço pessoal da mãe ou de aulas particulares. Entretanto, nem sempre isso é possível, e talvez a explicação dada pelo autor quanto à interrupção feita pela pedagogia invisível em relação às famílias de classes populares valha a pena ser levada em consideração, conforme veremos a seguir:

A pedagogia invisível contém uma teoria de transmissão diferente e uma nova tecnologia, que considera o próprio ensinamento informal da mãe, onde ele ocorre, ou os valores pedagógicos da mãe, irrelevantes quando não completamente nocivos. Há novos esquemas de leitura, matemática moderna substitui a aritmética, um expressivo estilo estético substitui a cópia de modelos. Se a mãe há de ser útil, ela deve ser re-socializada, ou mantida fora do caminho. (BERNSTEIN, 1984, p. 34).

Essa necessidade de ressocialização da família contribui para gerar novos conflitos entre família e escola, já que, para muitos pais, se o filho não está aprendendo como deveria, é apenas porque o professor não está ensinando. Essa tensão, gerada entre o nível de demanda dos pais (que os filhos dêem conta de se apropriarem do tipo de conhecimento que lhes garanta acesso à propriedade privada, e mantenham ou adquiram privilégios de classe) e a possibilidade de atendimento da mesma pela escola ainda implica os alunos, que precisam dedicar-se aos estudos com muito esforço. Bernstein sugere que a escola melhore a comunicação com as famílias, informando-lhes com maior freqüência e numa linguagem adequada o que e como se ensina e o porquê, e que se busque estimular as famílias de classes trabalhadoras a participarem do processo de educação dos filhos, valorizando suas contribuições.

Em relação à importância dada às tarefas de casa e à integração entre família e escola, Resende (2006) encontrou, em pesquisa 
realizada com famílias de classes popular e média, em duas escolas particulares de prestígio e uma estadual, de Belo Horizonte, uma expressiva valoração positiva em relação ao dever de casa e seu acompanhamento por parte dos pais, tanto os de classes populares como os de classe média, por entenderem que é com o dever de casa que o/a filho/a vai fixar o que aprendeu ou que esse seria o único momento em que ele/a estudaria fora da escola. Ou seja, esses pais percebem o dever de casa como atividade imprescindível para que as crianças dêem conta do aprendizado. É "um dos dispositivos curriculares por meio do qual a escola concretiza seu trabalho pedagógico" (RESENDE, 2006, p.1) e uma das formas de expressar a participação dos pais na vida escolar dos filhos. Uma das explicações para essa valorização do acompanhamento dos pais pode ser encontrada no reforço dado pela mídia a uma "ideologia de colaboração", divulgando pesquisas nas quais se vincula "o envolvimento dos pais na vida escolar dos filhos e o desempenho acadêmico destes" (ibid., p. 9). Esse acompanhamento, conforme discutido por Bernstein, não se dá sem dificuldades, por parte das famílias de classe popular, conforme nos esclarece Resende:

Os entrevistados [de classe popular] não deixam de expressar, em suas falas, as dificuldades desse acompanhamento, em função de fatores como pouco tempo dos pais, sua baixa escolaridade e conseqüente falta de domínio dos conteúdos escolares ou mesmo das formas discursivas utilizadas nos deveres. (RESENDE, 2006, p. 7).

Essa cultura de colaboração não é só idealizada pelas famílias, mas uma demanda das escolas. Entretanto, como explicitado por Resende, nem sempre é fácil para as famílias exercerem um acompanhamento efetivo. Famílias, tanto de classe média como popular, precisam aprender como auxiliar aos filhos na escola, conforme já mencionado neste texto. Para famílias de classe popular, a terceirização de serviços não é economicamente viável, por isso elas buscam o auxílio solidário da comunidade, ou solicitam a adequação das tarefas pela escola às suas possibilidades, conforme informa Resende (2006). Algumas famílias vêm se beneficiando de escolas públicas integrais, com acompanhamento de estudo, mas são minorias (RESENDE, 2006). Escolas particulares buscam atender a essas demandas, resolvendo as tensões geradas pelas mesmas, oferecendo serviços educacionais: aulas de apoio (recuperação), cursos conhecidos como 
integrais, onde a criança ou jovem passa um maior tempo no colégio realizando suas tarefas sob a supervisão de professores ou outros profissionais especializados, tornando-se, inclusive, mais autônomos em relação ao estudo (BRANDÃO, 2008).

$\mathrm{E}$ a escola? E os professores? Como percebem esses conflitos? Há alternativas de atuação para a escola e seus atores?

\section{REPENSANDO A ESCOLA E A FUNÇÃO DOS PROFESSO- RES, COM E PARA ALÉM DE BERNSTEIN}

Bernstein (1996, p. 94 e 126) apresenta as seguintes modalidades de práticas pedagógicas: (1) as analisadas na parte anterior, ou seja, aquelas vistas como conservadoras (ou tradicionais) e progressistas (ou centradas na criança), modalidades vistas como opostas entre si; (2) e aquelas que, não centradas na criança, são vistas como opostas dentro de uma mesma forma básica: "uma baseada na hierarquia de classe do mercado e outra baseada na hierarquia do conhecimento", as quais o autor denomina, respectivamente, "pedagogias visíveis orientadas pelo mercado" e "pedagogias visíveis autônomas" .

Em relação às duas primeiras modalidades, Bernstein defende que as pedagogias invisíveis, centradas na criança, têm o potencial de contribuir para que um menor número de crianças fracasse na escola, ao diminuir o compassamento, dando às crianças um maior tempo de aquisição de aprendizagens importantes, permitindo aos alunos maior tempo para sua expressão, de forma que possam se apropriar da modalidade de comunicação privilegiada pela escola: a análise. Bernstein, entretanto, ressalta que as pedagogias invisíveis são caras: demandam maior tempo de formação de professores, maior espaço físico nas salas de aula, menor número de alunos e um dispositivo pedagógico e de avaliação que se foque na progressão de cada aluno.

Quanto às outras duas modalidades, Bernstein afirma que ambas são condutoras de "estratificação social, de desigualdades sociais", porém, ideologicamente, a pedagogia orientada pelo mercado é "mais sinistra" (BERNSTEIN, 1996, p. 127). Em que sentido? A pedagogia visível autônoma se justifica com base no valor dos conhecimentos que transmite, é arrogante em relação a esse valor. Cortesão (2006, p. 54) afirma que os professores que vivenciam essa pedagogia são monoculturais, isto é, são os professores que "sabem", que dominam os conteúdos arbitrariamente designados como imprescindíveis. 
Conforme a autora afirma, são "tradutores" do saber elaborado por outrem. Para Cortesão (2006, p. 54), os alunos são receptores. Já a pedagogia visível orientada pelo mercado é mais complexa, ao incorporar críticas feitas à outra pedagogia, como o fracasso da escola, os currículos inadequados às diferentes classes. Entretanto, Bernstein (1996) afirma que um "compromisso explícito com uma maior possibilidade de escolha por parte dos pais e alunos não constitui uma celebração de democracia emancipatória, mas um sutil disfarce para a velha estratificação das escolas e dos currículos" (p. 128) Apesar de transmitir uma impressão de maior liberdade para as escolas e professores, esse tipo de escola está mais sujeito ao controle estatal; e, devido a esse controle, tem poucas chances de atender verdadeiramente às demandas de todas as crianças.

Bernstein antecipava situações que se encontram hoje presentes em muitos países, em que as escolas se encontram submetidas a modelos de avaliação externos rígidos e voltados para o mercado. $\mathrm{Na}$ Inglaterra, Stephen Ball (2005) relata que professores sentem-se muitas vezes desconfortáveis com as escolhas que se vêem obrigados a realizar. Para alguns, seguir programas que apenas visam a atender a sucesso em concursos, deixando de lado a discussão de atitudes, o aprofundamento de conteúdos mais importantes e o atendimento das demandas dos jovens, vai contra seus princípios éticos, contra o que consideram uma "boa prática e atender às necessidades dos alunos." (BALL, 2005, p. 551). Assim,

os professores acabam inseridos na performatividade pelo empenho com que tentam corresponder aos novos (e às vezes inconciliáveis) imperativos da competição e do cumprimento de metas. Os compromissos humanísticos do verdadeiro profissional - a ética do serviço - são substituídos pela teleológica promiscuidade do profissional técnico - o gerente. A eficácia prevalece sobre a ética; a ordem, sobre a ambivalência. (BALL, 2005, p. 548).

A preocupação com o desempenho leva também à "mercantilização do estudante". Estudantes de "baixo valor no mercado" - aqueles que apresentem dificuldades pedagógicas ou, como diria Bernstein, que necessitam de um tempo de aprendizagem um pouco maior do que o desejado, e aqueles com comportamento indesejado - acabam sendo expulsos dos sistemas escolares, de forma velada, pois interferem no desempenho geral. As escolas que fazem a opção 
ética de atender a crianças e jovens, sem levar em conta esse valor de mercado, correm o risco de perder seu lugar ao sol numa disputa competitiva, vendo alguns de seus alunos serem "comprados" com bolsas por instituições que buscam garantir alto lugar no ranking do vestibular X ou Y (BALL, 2005).

Contreras (2002, p. 42) ressalta que a proletarização ideológica do trabalho do professor ocorre quando há "a perda de controle sobre os fins e propósitos sociais aos quais o trabalho se dirige". Cortesão (2006, p. 99) afirma que mesmo professores progressistas, utilizandose de pedagogias invisíveis, podem agir de forma reprodutora, ao não adequarem o ensino às necessidades dos educandos. Para a autora, a saída não se dá em se assumir, enquanto professor, como "agente messiânico do Estado", papel esse que se quer destinar aos professores, sabendo-se, porém, antecipadamente, que é um papel impossível, uma vez que a sociedade capitalista pressupõe relações de classe que não podem ser eliminadas via educação. Assim, cabe aos professores explorar "espaços, ainda que limitados, de autonomia" (ibid., p. 99).

De que forma os professores poderiam recuperar o sentido social de seu trabalho e sua autonomia? Cortesão (2006) propõe que os professores ultrapassem o papel de "tradutores" de um saber produzido por outros. Para ela, somente se tornando professores multiculturais, capazes de transformar as diferenças sociais, culturais e étnicas em fonte de riqueza pedagógica, professores e alunos se tornarão "bilíngües culturais", contribuindo para a ampliação dos horizontes sociais, culturais e cidadãos de todos os envolvidos no processo. A autora sugere que professores possam se tornar produtores de conhecimento científico, sobre a área de conhecimento na qual trabalham, e de conhecimento sócio-antropológico, sobre seus alunos. Além disso, é necessário decidir-se sobre as finalidades da educação, no que a sociedade também está implicada, pois uma educação emancipatória não poderá se dar da forma que se preconiza uma educação voltada para os interesses neoliberais. Para Cortesão, o professor tem um papel indispensável numa nova ordem social e, para isso, não pode limitar-se a ensinar as "regras do jogo"; seu papel é ensinar aos jovens o ofício do pesquisador, mostrando-lhes que é possível alterar as regras.

Um trabalho orientado dessa forma é diferenciado, quem o realiza tem a preocupação de aproximar-se dos problemas do alunado, atendendo a características socioculturais e etárias dos educandos. 
É um trabalho desafiador e estimulante para o desenvolvimento dos alunos, tendo maior possibilidade de implicá-los "na construção de seu próprio saber, no seu desenvolvimento global e no fortalecimento da consciência dos seus direitos como cidadãos" (CORTESÃO, 2006, p. 122), diminuindo o mal-estar educativo. É um trabalho que pretende transformar os alunos em investigadores sociais críticos, mas, para isso, há que se criar dispositivos de diferenciação pedagógica adequados a cada situação, há que se buscar atender às características sócio-culturais e etárias dos alunos.

Cortesão sugere que se procure vivenciar caminhos percorridos com sucesso na Pós-Graduação, em que se aplicam os seguintes princípios: (a) é uma situação de ensino-aprendizagem atravessada por atividades de pesquisa, na linha da dupla produção de conhecimento (na qual o professor produz conhecimento científico e conhecimento sócio-antropológico sobre os alunos); (b) é uma atividade na qual pesquisa e ação "interatuam e se interinfluenciam, estando, portanto, próxima da Investigação-Ação" (CORTESÃO, 2006, p. 113-4); (c) de acordo com a etapa em que encontra o projeto, o orientador deverá adequar seu trabalho e sua ação a cada orientando, estimulando-o à análise crítica e à criação; (d) assim, o "fazer como eu" (o modelo), para garantir o aprendizado do ofício da pesquisa, deverá garantir uma margem de liberdade ("o não fazer como eu"), para tornar certas a criação, a originalidade, a reapropriação do conhecimento pelo orientando, pois esse é o salto criativo original que parece existir na atividade de pesquisa (CORTESÃO, 2006, p. 115); (e) o professor facilita esse salto, se puder questionar o que deve no momento preciso e utilizar-se da "pedagogia do silêncio" (idem, p. 115), que "proporciona a privacidade potenciadora do ato criativo" (BOURDIEU, citado por CORTESÃO, 2006, p. 116); (f) essa forma de se ensinar a fazer pesquisa não pode ser estandardizada, é adaptada a cada situação de trabalho, "algo que se aproxima do que se designou por dispositivos de diferenciação pedagógica". (CORTESÃO, 2006, p. 116).

Canário (2005) propõe que as escolas se tornem espaços de aprendizagem coletiva, contextos de formação. Defende que, quando se pensa que os professores são os destinatários das reformas, que "devem" mudar para se adequarem ao esperado, coloca-se a mudança como um processo focado na "inovação como produto" (CANÁRIO, 2005 , p. 99), processo que ignora a escola como totalidade. Ignora porque considera que há problemas que podem ser resolvidos de forma 
isolada e individual, quando, segundo o autor, os problemas precisam ser vistos de forma sistêmica. Canário defende que a promoção de mudanças implica a necessidade de a escola mudar a forma de pensar a ação, como ações interdependentes, que se articulam. Para ele, professores e escolas mudam simultaneamente, numa perspectiva "ecológica" de mudança. Mudam-se os processos de interação social. O autor defende a importância da pesquisa científica para "otimizar as potencialidades formativas do contexto de trabalho", e como forma de o professor construir sentido e se tornar autor de sua prática. Sugere mudanças para que os investigadores das universidades se aproximem dos professores, numa perspectiva próxima à proposta por Lüdke e Cruz (2005, p. 98), que indicam a pesquisa como "um componente a mais na formação do professor", que pode "conferir ao professor uma ótima condição para o exercício de uma atividade criativa e crítica, onde há o questionamento, mas, também, a indicação de soluções para os problemas investigados". As autoras propõem, inclusive, a realização de pesquisas "híbridas", em parceria com a Universidade, como uma das formas de se aproximar a escola básica da universidade, ou seja, propõem trabalhos realizados em parceria por docentes da escola básica e seus professores de mestrado.

Canário (2005), Lüdke e Cruz (2005) reforçam a importância de o professor assumir uma postura crítica e reflexiva sobre sua ação, aproximando-se da visão do professor como investigador-social-crítico, proposta por Cortesão (2006). Esses autores têm em comum a percepção da importância da pesquisa na formação do docente e suas contribuições para a comunidade educativa. Lüdke e Cruz ressaltam a importância da pesquisa para o professor assumir sua formação, tornando-se profissional autônomo; Cortesão destaca a relevância da pesquisa do professor, que produz conhecimento científico e sobre seus alunos, e a importância desta para a formação dos alunos, que precisam aprender o "ofício de pesquisador", para poderem "alterar as regras do jogo"; e Canário defende a pesquisa como uma das formas de aprendizagem coletiva nas organizações de ensino, capaz de contribuir para que o professor seja um "inovador".

Sobre esse último aspecto, é importante clarificar que, para Canário (2005, p. 119), ser um "bom profissional" é diferente de ser "um educador inovador". Um bom profissional é aquele que pode ser avaliado, sua ação segue um padrão. A questão é que hoje, em educação, não há mais normas estáveis, o que faz com que os professores 
produzam, ao mesmo tempo, normas e práticas. Um bom profissional serviria para a época da escola das certezas (CANÁRIO, 2005), nas quais havia consenso sobre os fins da educação, normas e projetos. Numa "era de incertezas", precisa-se do "educador inovador", aquele que anda no "terreno do imprevisível", que constrói práticas e normas que não existem ainda e precisa "criar dispositivos permanentes que permitam criar práticas que depois se revelarão boas ou más e que irão ser corrigidas" (CANÁRIO, 2005, p. 119).

\section{CONCLUINDO: QUE SAÍDAS TÊM AS ESCOLAS E SEUS PROFESSORES?}

Bernstein (1996, p. 94) já argumentava que tanto nas pedagogias visíveis quanto nas invisíveis é "provável que os pressupostos de classe existentes" sejam reproduzidos, ou seja, o fato de uma escola se autonomear progressista, ou de utilizar pedagogias assim consideradas, não significa necessariamente que não produza práticas estratificadoras, reprodutoras de desigualdades sociais. Seus professores podem ser "monoculturais" (CORTESÃO, 2006), sem autonomia, presos a projetos com que por vezes não concordam, mas aos quais acabam se acorrentando por não conseguirem sair da facticidade de sua própria prática. Bernstein afirma que as pedagogias visíveis tendem a distribuir diferentes formas de consciência, e que se as crianças que não conseguiam atender às regras de seqüenciamento caíssem nos sistemas de recuperação, provavelmente estariam presas à dependência do discurso oral do professor, limitadas por "habilidades locais, dependendo do contexto, presas ao contexto; por um mundo de facticidade" (BERNSTEIN, 1996, p. 111). Essas crianças provavelmente nunca ultrapassarão um discurso "seguro", nunca perceberão que "o núcleo do discurso é a possibilidade de novas realidades" (ibid., p. 111). Muitos professores também não o sabem.

É possível que os professores se beneficiem do conceito de autonomia profissional de Contreras (2002), o qual depende da "sensibilidade moral" em reconhecer a própria parcialidade e limites, inclusive na compreensão dos outros. $\mathrm{O}$ autor defende que esse reconhecimento exige trabalho, uma libertação auto-imposta, por parte do professor. Para ele, "[...], a autonomia profissional perde seu sentido de auto-suficiência para aproximar-se da solidariedade" (CONTRERAS, 2002, p. 188). Cortesão (2006) indica um caminho que passa pelo reconhecimento das diferenças, pela superação do valor 
da homogeneidade na sala de aula, para que a turma e o professor se beneficiem da riqueza da diversidade. Canário (2005) sugere que a escola se torne um contexto de formação, que se mude o contexto e professores ao mesmo tempo. Para isso, todos precisam solidarizar-se com o colega e, principalmente, com o aluno, que, como bem afirma Canário (2005), não é um inimigo.

Como uma primeira etapa do processo, é importante que os professores se perguntem: "Acredito que todos os meus alunos são capazes de aprender? Estou buscando me relacionar e interagir com todos, ensinar a todos, ou apenas aos que 'falam minha língua', que percebo capazes? Ensino o que e por quê? Estou de fato oferecendo um espaço de aprendizagem na sala?"

Essas perguntas se colocam como fundamentais, conforme demonstra Sá Earp (2006) em sua tese de doutorado. Em sua pesquisa de campo, de cunho etnográfico, sobre a construção da repetência na sala de aula, a pesquisadora revela uma estrutura que denominou "centro-periferia". Essa estrutura descreve as formas de o professor interagir com os alunos. Sá Earp encontrou três tipos da estrutura: a "periferia", em que o professor dá a aula, não se indagando se a turma está aprendendo, chegando mesmo a duvidar da capacidade de aprendizagem dos alunos; a estrutura "centro-periferia", na qual o professor elege alguns alunos para ensinar; e a estrutura "centro", em que todos os alunos são alvo da atenção do professor, que os percebe capazes de aprender e busca adequar a linguagem, o ritmo, os desafios apresentados às necessidades de cada um. Enfim, é imprescindível que cada professor e seus colegas parem para refletir seriamente sobre a forma que vêem cada aluno e sobre sua ação em sala, para promover o aprendizado de cada um e de todos os alunos.

Em segundo lugar, a escola é uma comunidade, um contexto de formação que não está sendo bem aproveitado. Para que o potencial formativo tanto dos professores como dos alunos possa ser maximizado, é necessário que se assuma que a autonomia profissional docente não pode ser individual, ou seja, o professor não pode se preocupar apenas com sua sala de aula, deixando de refletir sobre o projeto da escola e as demandas sociais. São imprescindíveis a solidariedade e o comprometimento com a sociedade, é necessário trabalho para superar as distorções ideológicas (CONTRERAS, 2002), provocadas, inclusive, pelas distribuições de diferentes formas de consciência, conforme nos alerta Bernstein (1996). Assim, cada docente precisa se propor a abrir mão de uma parcela de sua autonomia, no sentido 
de poder refletir e estar disposto a rever seus pressupostos, os limites do seu campo de conhecimento e confrontar suas ações e descobertas à análise crítica de colegas, buscando práticas mais adequadas para o aprendizado dos alunos.

Em terceiro lugar, definida a ação docente como parte de um projeto coletivo, pode-se refletir sobre os ganhos de uma prática pedagógica mista, conforme sugerido por Bernstein (MAINARDES, 2003). Mainardes apresenta as características dessa prática, em seu Projeto de DiferenciAção ${ }^{3}$ e a autora ousará relacioná-las a outras discussões previamente feitas ao longo deste trabalho. Práticas pedagogias mistas pressupõem que o professor diminua o compassamento (o ritmo) do processo de ensino-aprendizagem, proporcionando momentos para que os alunos que ainda não aprenderam determinados conteúdos possam aprendê-los, o que demanda conhecimento do nível, necessidades e características dos alunos, para que se possam oferecer a eles dispositivos de diferenciação das atividades propostas. Além disso, os professores precisam diminuir a classificação entre os conteúdos, permitindo aos alunos integrarem saberes.

Outra característica da prática pedagógica mista é que o discurso dos alunos deve se fazer presente no cotidiano. Cortesão (2006) deu boas "pistas" sobre a relação profícua entre o "faz como eu" e a criatividade necessária para $\mathrm{o}$ ato de aprender e produzir novos saberes. Práticas pedagógicas mistas também demandam do professor a capacidade de relacionar conhecimentos acadêmicos a não-acadêmicos, o que permite também a superação do monoculturalismo por parte do professor e dos alunos. Professores atentos ao que ocorre no mundo e nos diferentes grupos de origem dos alunos têm maior possibilidade de trazer para a sala reflexões mais plausíveis e relevantes para os alunos, tornando-se bilíngüe culturalmente e permitindo aos alunos que também se tornem bilíngües. Isso favorece também o processo de democratização escolar, diminuindo conflitos com as famílias, e complementa outro aspecto das pedagogias mistas, qual seja, uma fraca hierarquia professor-aluno. Fraca hierarquia não pressupõe confusão de papéis, mas clareza dos mesmos e de seu sentido: o professor torna-se aquele técnico, é o mais experiente, como nos aponta Cortesão (2006), sem, entretanto, anular as vozes

${ }^{3}$ Para maiores esclarecimentos e informações sobre a diversificação em sala de aula e o uso de práticas pedagógicas mistas, consultar Mainardes (2003 e 2007). 
dos alunos e sem omitir seu saber e sua orientação, quando se fazem importantes. É, assim, uma relação que não dá espaço para o abuso do poder. A avaliação deve ter critérios claros e permitir o avanço do aluno, pois de nada adianta avaliar se não for para propor ações que sirvam para o crescimento do aluno.

Enfim, como preconiza Cortesão (2006), para que o professor assuma seu lugar em uma época de mudanças, é necessário que ele possa produzir conhecimento e adequá-lo às necessidades, faixas etárias, grupos de origem de seus alunos. A pesquisa mostra-se fundamental para essa atuação docente. É importante que o professor possa assumir a autoria de parcelas do conhecimento que transmite para os alunos e sobre os alunos, e sobre o como atuar em sala, tornar-se, enfim, um investigador-social-crítico.

É importante destacar que, se em sua ação e prática, a ação coletiva para a construção de uma escola - e sociedade - mais justa e democrática ainda não se mostra completamente viável, cabe a cada um procurar fazer sua parte, questionando, no seu fazer, se segue o caminho que considera ideal, e ouvindo outras pessoas - família, alunos e colegas - sobre qual seria esse ideal. Não há caminho perfeito e, como bem diz Elias (1994, p. 138), "a pessoa não se descobre repentinamente na meta desejada. O importante é a direção em que está indo".

Agradecimentos

A autora agradece, em especial, à professora Maria Inês Marcondes, pela inspiração e sugestões, e às colegas Vânia Leite e Sara Moitinho, por suas releituras e contribuições.

\section{REFERÊNCIAS}

BALL, S. J. Profissionalismo, gerencialismo e performatividade. Cadernos de Pesquisa, São Paulo, v. 35, n. 126, 539-564, set./dez. 2005.

BERNSTEIN, B. Classes e pedagogia: visível e invisível. Cadernos de Pesquisa, São Paulo, v. 49, p. 26-42, maio. 1984.

. A estruturação do discurso pedagógico: classe, códigos e controle. Rio de Janeiro: Vozes, 1996.

BRANDÃO, Z. Do survey ao trabalho de campo. Análise preliminar. Boletim SOCED. Rio de Janeiro, n. 5, p.1-20, ano 2008. Disponível em: http://www.maxwell.lambda.ele.puc-rio.br/cgi-in/PRG_0599.EXE/11153. PDF?NrOcoSis $=360048 \mathrm{CdLinPrg}=$ pt. Acesso em: 23 mar. 2008. 
Professores, alunos e suas famílias: uma análise da escola a partir de idéias de Basil Berstein

CONTRERAS, J. A autonomia de professores. São Paulo: Cortez, 2002.

CORTESÃO, L. Ser professor: um ofício em extinção? São Paulo: Cortez; Instituto Paulo Freire, 2006. (Coleção Prospectiva; v.6)

ELIAS, N. A sociedade dos indivíduos. Rio de Janeiro: Jorge Zahar Ed., 1994.

FORQUIN, J. C. Escola e cultura: as bases sociais e epistemológicas do conhecimento escolar. Porto Alegre: Artes Médicas, 1993.

LÜDKE, M.; CRUZ, G. B. da. Aproximando universidade e escola de educação básica pela pesquisa. Cadernos de Pesquisa. São Paulo, v. 35, n. 125, 2005.

MAINARDES, J. Projeto diferenciAção: criando classes mais igualitárias por meio do trabalho diversificado. Ponta Grossa: UEPG, 2003. Disponível em: http://www.uepg.br/gppepe. Acesso em: 20 mar. 2008.

2007.

Reinterpretando os ciclos de aprendizagem. São Paulo: Cortez,

NOGUEIRA, M. A. A escolha do estabelecimento de ensino pelas famílias: A ação discreta da riqueza cultural. Revista Brasileira de Educação, Rio de Janeiro, n.7, p. 42-56, jan./abr. 1998.

RESENDE, T. F. Dever de casa: questões em torno de um consenso. In: REUNIÃO ANUAL DA ANPED, 29, Caxambu, 2006. Disponível em: http:// www.anped.org.br/ reunioes/29ra/trabalhos/trabalho/GT14-2625--Int.pdf. Acesso em: 26 jul. 2007.

SÁ EARP, M. de L. A cultura da repetência em escolas cariocas. 2006. 333 p. Tese (Doutorado em Antropologia Cultural)-. UFRJ, Instituto de Filosofia e Ciências Sociais, Programa de Pós Graduação em Antropologia e Sociologia, Rio de Janeiro, 2006.

SANTOS, L. L. de C. P. Bernstein e o campo educacional: relevância, influências e incompreensões. Cadernos de Pesquisa, São Paulo, n. 120, nov. 2003.

TEDESCO, J. C.; TENTI FANFANI, E. Novos docentes e novos alunos. In: Ofício de professor na América Latina e Caribe: Trabalhos apresentados na Conferência Regional O Desempenho dos Professores na América Latina e no Caribe, Novas Prioridades, Brasília, julho de 2002. São Paulo: Fundação Victor Civita; Brasília: UNESCO Brasília, 2004.

Encaminhado em: 08/07

Aceito em: 11/07

62
62 Olhar de professor, Ponta Grossa, 11(1): 43-62, 2008. 